\title{
Las características suburbanas del sector noroeste del Área Metropolitana de Madrid
}

\author{
Carmen Muguruza cañas
}

Los núcleos del sector noroeste del Área Metropolitana de Madrid deben su fisonomía y entidad al desarrollo que se produjo en torno a Madrid, como expresión de su crecimiento hacia la periferia. Así pues, estos núcleos tienen su origen actual fundamentalmente en el proceso de formación del Área Metropolitana y en las condiciones especificas e irrepetibles que dieron lugar a su acelerado crecimiento en las décadas de los sesenta y setenta.

Si esto es así para todos los municipios que hoy configuran las distintas zonas y coronas del Área Metropolitana Madrileña, el rasgo específico para los municipios del noroeste es que son municipios en los que se puede hablar con una cierta propiedad de un proceso de "suburbanización". Este concepto urbanístico hace referencia a lo que coloquialmente se entiende por "urbanizaciones", y que se asimilan con un conjunto limitado de tipologías de edificación que van desde el chalet aislado con parcela individual a los bloques de poca altura ordenados alrededor de espacios comunes privados. Este tipo de vivienda va dirigido fundamentalmente a una demanda compuesta por clases medias y altas.

El desarrollo de esta suburbanización, cuyo peso en el Área Metropolitana Madrileña es cuantitativamente pequeño en porcentaje de viviendas y población, es, sin embargo, importante en lo que se refiere a la ocupación del espacio, en términos de suelo. No es casualidad, como veremos, que el proceso de suburbanización se desarrolle sobre todo en la zona oeste del Área Metropolitana, y en menor medida en la zona 
norte, ahí donde se encuentran las mejores condiciones medioambientales, y la mayor proximidad a la Sierra.

Las bases del proceso de suburbanización hay que verlas en el papel que la zona ha jugado con respecto al crecimiento madrileño. Dentro del desarrollo urbanístico de Madrid, la zona noroeste ha tenido desde siempre un puesto de privilegio.

Ya desde finales del siglo xIx el crecimiento de Madrid hacia el Norte tuvo una consideración prestigiosa. El Plan Castro (1868) consagra el sector norte de la ciudad (futuro barrio de Salamanca y Castellana), con sus palacetes y construcciones de mejor calidad, como una de las zonas destinadas a la incipiente burguesía madrileña. Mientras que el Sur lo reserva, en su conocida zonificación, a lugar de residencia del proletariado urbano. Este hecho se vio reforzado por la localización de la industria en el sur del municipio, en torno a las estaciones de ferrocarril (cinturón que iba desde Príncipe Pío a Atocha).

Así pues, la polarización clasista de la ciudad aumenta como fenómeno típico de la ciudad industrial. "Esta polarización va a construir una caracteristica particularmente extrema en el desarrollo de Madrid, en donde se dará una evidente segregación de la población trabajadora hacia el Sur, zona de peores condiciones urbanísticas, al tiempo que se produce la congelación del crecimiento hacia el noroeste» '.

Va a ser a partir de la posguerra cuando la vocación residencial de alta calidad se consolida en los municipios próximos al eje de la Coruña. El Plan del 46 es plenamente consciente de las posibilidades urbanísticas de la zona. Su encuadre en un marco físico privilegiado, cuyo telón de fondo lo constituyen la Sierra y los "paisajes velazqueños", la hacen ideal para localizar allí un espacio residencial para la élite madrileña, constituida por los segmentos más altos de la sociedad, que el régimen intenta favorecer.

La concepción urbanística y la voluntad de segregar a la población madrileña del Plan del 46, queda perfectamente reflejada en el siguiente párrafo y en la Figura 1.

«Dentro de la disposición nuclear, compuesta por un recinto principal y recintos satélites, que pudiera dar lugar a una ordenación fría y geométrica, la geografía de la comarca establece determinantes que influyen

1 E. Leira, J. Gago y I. Solana: “Madrid: cuarenta años de crecimiento". Ciudad y Territorio, $n .^{\circ} 2 / 3,1976$, p. 48. 


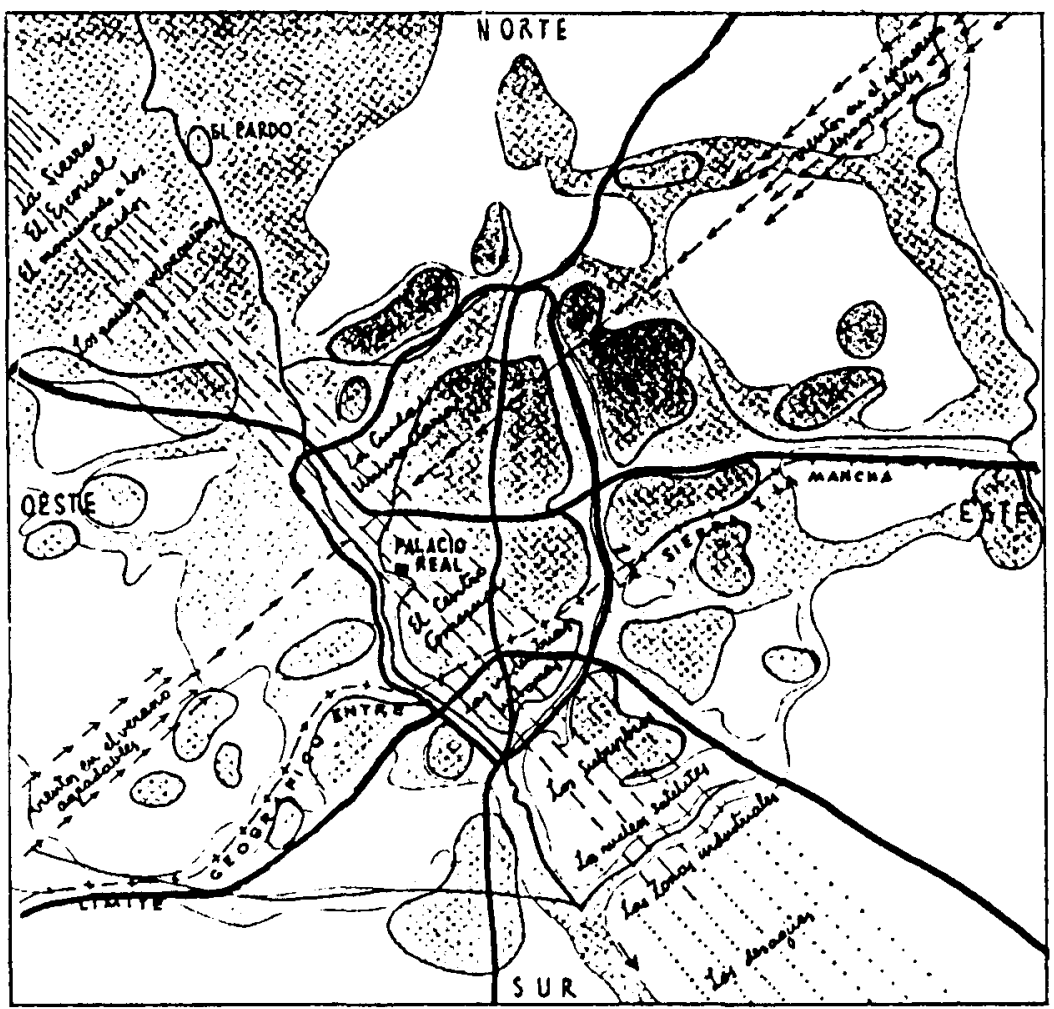

Figura 1.-Esquema del Plan del 46.

Fuente: Recuperar Madrid.

de manera decisiva en la organización urbana. Madrid está en la línea límite que, paralela a la sierra, separa las estribaciones de ésta de las llanuras de La Mancha y participa de la fisonomía de ambas regiones, tan diferentes entre sí. En la misma dirección de esta línea soplan los vientos dominantes. Perpendicularmente a estas direcciones se aprecia la existencia de una jerarquía de atractivos naturales, de manera que los sectores del Noroeste gozan de los paisajes agradables inmortalizados por el pincel de Velázquez, en tanto que los del Sudeste nos muestran toda la sequedad de la Meseta... El planeamiento urbanístico defiende y acentúa este orden natural para obtener una gran creación urbana plena de sentido, de armonía y variedad" ${ }^{2}$.

\footnotetext{
${ }^{2}$ Memoria del Plan Bidagor, p. 42.
} 
En este período de grandes necesidades de vivienda debido a las destrucciones de la guerra, y al incipiente proceso de inmigración que sufre Madrid, las escasas viviendas construidas van dirigidas a clases sociales de renta superior. De este modo, aunque tímidamente, comienzan a crearse en este sector los primeros espacios suburbanos para la oligarquía madrileña. "Como plasmación externa de la polarización clasista, la oligarquía va a empezar a crear sus ghettos suburbanos, aunque las malas condiciones de las salidas de Madrid tan sólo los permiten plantear: Puerta de Hierro, La Florida, Aravaca, .., de escasa importancia." ' ${ }^{3}$. La escasez de medios de transporte, así como el limitadísimo segmento de la población madrileña que puede acceder a este tipo de hábitat, hacen imposible poder hablar de un crecimiento suburbano a la manera anglosajona, pero la "preservación" de este sector como área de buenas condiciones urbanísticas, hacian presagiar que cuando se produjera un despegue económico en el país, y las condiciones de transporte mejorasen, se convertiria en una de las áreas en las cuales se podía localizar un urbanismo de prestigio.

Asimismo, la burguesía madrileña ha tenido un tradicional apego a vivir en la zona de Ensanche, este apego no sólo ha estado motivado por razones "sentimentales", sino que también han influido hechos de índole económica. La congelación de alquileres hasta fecha reciente y el mantenimiento de magníficos pisos con renta antigua, han hecho que la burguesía madrileña fuese reticente a abandonar la zona de Ensanche.

La "preservación" del sector noroeste a posibles actuaciones urbanísticas de tipo social, parece ser que no fue casual, sino que existen una serie de indicios que hacen pensar que hubo cierta voluntariedad. La Comisaria del Plan de 1946, llevó a cabo una serie de expropiaciones en el borde de la ciudad, en teoría para reservar suelo para zona verde. Todos los miles de hectáreas expropiadas van a constituir más tarde suelo en donde se localizarán las grandes operaciones urbanisticas de vivienda de tipo social y de promoción oficial que se llevarán a cabo posteriormente (Manoteras, Canillas, San Blas, Palomeras, Villaverde). Sorprendentemente, las expropiaciones no afectaron al eje noroeste, eje en el cual las expropiaciones hubiesen sido mucho más fáciles, ya que se trata de una zona de gran propiedad (ver Cuadro l) y se hubiesen salvado los escollos de un proceso que afectó a centenares de pequeños propietarios, con lo que ello implica de complejidad jurídica. De esta manera, la zona noroeste quedó prácticamente fuera de la promoción de

${ }^{3}$ G. Leira, J. Gago y I. Solana: Obra citada, p. 48. 
Las características suburbanas del sector noroeste...

CUADRO I. LA GRAN PROPIEDAD EN LA ZONA

\begin{tabular}{lccc}
\hline & \multicolumn{3}{c}{ Más de 250 Hectáreas } \\
\hline & Prop. & $\begin{array}{c}\text { Superficie total } \\
\text { Ha. }\end{array}$ & Superficie media \\
\hline Boadilla ................ & 4 & 2.303 & 575,7 \\
Majadahonda ............ & 1 & 570 & 570,0 \\
Pozuelo ................. & 2 & 1.099 & 549,5 \\
Las Rozas ............... & 5 & 2.222 & 444,4 \\
Villanueva de la C. ....... & 3 & 1.223 & 311,0 \\
Villanueva del Pardillo ... & 1 & 311 & 311,0 \\
\cline { 2 - 3 } & 16 & 7.728 & 483,0 \\
\hline
\end{tabular}

Fuente: M. VAlENzUELA: Urbanización y crisis rural en la Sierra Madrileña.

CUADRO I. LA GRAN PROPIEDAD EN LA ZONA (Continuación)

\begin{tabular}{|c|c|c|c|c|c|}
\hline & \multicolumn{3}{|c|}{ De 100 a 250 Has } & \multicolumn{2}{|c|}{ Totales } \\
\hline & Prop. & $\begin{array}{c}\text { Superf. } \\
\text { total Ha. }\end{array}$ & $\begin{array}{l}\text { Supert. } \\
\text { Media }\end{array}$ & $\begin{array}{c}\text { Superf. } \\
\text { (Ha.) }\end{array}$ & $\begin{array}{l}\text { \% Total } \\
\text { Munic }\end{array}$ \\
\hline Boadilla & 4 & 601 & 150,2 & 2.904 & 62,0 \\
\hline Majadahonda . & 4 & 590 & 147,5 & 1.160 & 30,7 \\
\hline Pozuelo. & 5 & 666 & 133,2 & 1.765 & 41,4 \\
\hline Las Rozas . .............. & 11 & 1.654 & 150,4 & 3.876 & 65,8 \\
\hline Villanueva de la C. .. & 4 & 668 & 167,0 & 1.891 & 55,1 \\
\hline \multirow[t]{2}{*}{ Villanueva del Pardillo. } & 3 & 401 & 136,6 & 712 & 27,2 \\
\hline & 31 & 4.580 & 147,7 & 12.308 & 56,7 \\
\hline
\end{tabular}

Fuente: M. VAlenzUela: Urbanización y crisis rural en la Sierra Madrileña. 
tipo oficial. Asimismo, el Plan del 46 intentó y consiguió que la industria se situara en los municipios del Sur de Madrid.

Así, la periferia noroeste se va distanciando notablemente del desarrollo seguido por el cinturón industrial.

El crecimiento del sector es muy lento hasta los años sesenta, en los cuales aparece un fenómeno que va a ser protagonista en el desarrollo urbano de la zona: el fenómeno de la segunda residencia. Analizadas suficientemente las razones de este hecho en la Tesis de $M$. Valenzuela ${ }^{4}$, vamos a reseñar aquí simplemente la importancia que ha tenido la segunda residencia como fenómeno antecesor de la vivienda permanente, y por lo tanto, como motor importante en la urbanización del área.

A partir de mediados de los años sesenta, Madrid sufre un proceso de industrialización muy fuerte que conmociona a la estructura urbana pre-existente. Madrid pasa a ser no sólo un centro político y de servicios, sino un auténtico centro industrial, lo cual va a suponer un aumento desconocido de la inmigración hacia la capital. Los contingentes de población llegados a Madrid impiden que se cumplan las previsiones realizadas en los Planes Nacionales de Vivienda, la iniciativa oficial carecía de capacidad de gestión suficiente para abordar el problema de crecimiento de Madrid. Asi, a mediados de los años sesenta comienza una febril actividad inmobiliaria por parte de la iniciativa privada. El crecimiento espacial de Madrid y sus repercusiones en los municipios del entorno hacen que hablemos de Madrid como una auténtica ciudad urbanizante. «El proceso de urbanización no se plasma en el espacio de una manera uniforme, sino que se produce un proceso de urbanización del mundo rural que adquiere una intensidad decreciente conforme nos alejamos de la capital' ${ }^{5}$.

A mediados de los años sesenta se va a producir el crecimiento metropolitano de Madrid, la particular forma de este crecimiento ha hecho que se denomine como crecimiento a "saltos". "En los últimos años sesenta, se configura la actual área metropolitana. El crecimiento, tanto en población como en ocupación del suelo, va centrándose en la periferia metropolitana» ${ }^{6}$. El salto de la promoción inmobiliaria a la corona metro-

${ }^{4}$ M. Valenzuela, Urbanización y crisis rural en la Sierra de Madrid. Madrid, IEAL, 1977.

$5 \mathrm{~J}$. EstébANEZ, "Las transformaciones del medio rural en la provincia de Madrid". " Jornadas sobre la Provincia de Madrid. Diputación de Madrid.

${ }^{6}$ E. Leira, J. Gago, y I. Solana: obra citada, p. 55. 
politana se advierte a mediados de los sesenta, apoyándose en la red de transporte existente. Los rasgos fundamentales de este "salto" se pueden ver en una búsqueda de suelo barato, así como en la previa existencia de una mínima infraestructura de apoyo que evitara al máximo inversiones en equipamiento. De esta forma, se dejan vacantes grandes extensiones de terrenos periféricos a Madrid y se edifica en los municipios exteriores donde había una carretera y un núcleo mínimo de servicios. Así crecieron hasta su actual magnitud los municipios del alfoz madrileño: Leganés, Getafe, Alcorcón, San Fernando, Coslada, Torrejón, Alcobendas, San Sebastián, y posteriormente, Alcalá, Móstoles, Fuenlabrada, Pinto, Parla, ... El resultado de este proceso es un crecimiento muy nucleado que se apoya en la red radial. Un proceso complementario es la progresiva segregación de actividades y funciones, así los núcleos del Sureste del Área Metropolitana de Madrid juegan un papel de ciudad dormitorio e industrial, así como los núcleos del corredor del Henares, mientras que los municipios de Noroeste inician su papel de núcleos residenciales de alta calidad.

Un hecho urbanístico que tuvo particular relevancia en la configuración del modelo metropolitano madrileño fue el Plan General de Ordenación Urbana del Area Metropolitana Madrileña de 1963. Este Plan se concibió dentro de una filosofía de descongestión de Madrid, planteando un crecimiento espacial de forma compacta y cerrada, con la limitación física de un anillo verde que habría de formar el borde y terminación de la ciudad. "Esta rigidez iba a estar en contradicción con las altas necesidades de implantación de nuevas industrias del gran período desarrollista que sucedió al Plan, y con el gran giro decisivo hacia la promoción privada de viviendas que causó el salto del crecimiento hacia la periferia" ${ }^{7}$.

Los puntos del Plan del 63 que tuvieron una repercusión en la zona de estudio son los siguientes:

- La creación de una red viaria con reforzamiento de los accesos previstos en el Plan del 46 (red fundamentalmente radio-concéntrica).

- La segregación de la industria en grandes polígonos: Villaverde, Vallecas, Vicálvaro, Canillejas, San Fernando de Henares, Torrejón de Ardoz.

- Delimitación de un anillo verde.

7 COPLACO: Directrices de planeamiento territorial. Madrid, 1981, p. 89. 
Los dos primeros puntos aumentaron la accesibilidad de la zona, y evitaron la instalación de la industria en los municipios del noroeste, localizándose ésta preferentemente en el Sur y Sureste madrileño.

La existencia de un anillo verde va a tener una importancia trascendental en los municipios objeto de estudio. La creación del anillo verde no garantizaba la conversión de los terrenos en parques públicos, sino tan sólo la aparición de zonas arboladas que limitaban la expansión de la ciudad, y existió una incapacidad de la Administración pública para llevar a cabo la expropiación de dichos terrenos. Los grandes propietarios de la zona noroeste, ya en el mismo año de aprobación del Plan, presentaron alegaciones al mismo, de tal manera que consiguieron que fuera aprobada una normativa que modificaba el Plan en el sentido de permitir la edificación de vivienda unifamiliar de lujo en actuaciones de 50 hectáreas, aumentando la segregación social de la población madrileña. La creación de urbanizaciones de alto standing fue la tónica de estos municipios en los años setenta. Estas operaciones urbanísticas se vieron favorecidas por la conversión de la carretera de la Coruña en una vía rápida $(\mathrm{N}-\mathrm{VI})^{8}$.

De esta manera surgen en el sector noroeste una serie de parcelaciones sobre suelo rústico, en su mayoría grandes fincas de un solo propietario, que suele actuar como promotor. Estas parcelaciones eran posteriormente legalizadas por COPLACO o mediante la tramitación de Planes Parciales, gracias a la flexible normativa del Plan del 63. El caso más llamativo es el del municipio de Pozuelo, en el que se tramitaron un total de 14 Planes Parciales sobre terreno destinado al anillo verde, como se puede ver en el Cuadro II, un total de 1.119 hectáreas han sido absorbidas por distintas actuaciones en Pozuelo.

Todo ello ha dado como resultado en la zona un proceso de urbanización puntual, creándose urbanizaciones de forma aislada y comprometiéndose grandes cantidades de suelo. "La magnitud de suelo comprometido y sujeto a especulación en los años setenta constituye lo que se ha llamado el cáncer de suelo expectante" ${ }^{9}$.

Las promociones de las urbanizaciones en la zona noroeste estaban en manos privadas, dándose todas las formas de obtención del suelo y promoción, desde el pequeño propietario metido a promotor en su par292.

${ }^{8}$ R. Fernandez Duran: Transporte, espacio y capital. Madrid, 1980. Nuestra Cultura, p.

${ }^{9}$ E. Leira, J. Gago, y I. Solana.: Obra citada, p. 59. 


\section{CUADRO II. ACTUACIÓN SOBRE EL ANILLO VERDE} (Pozuelo de Alarcón)

\begin{tabular}{|c|c|}
\hline Plan Parcial & Has. \\
\hline Pinar del Plantio . & 4,30 \\
\hline Las Encinas ....... & 66,10 \\
\hline Monteclaro ........ & 129,50 \\
\hline 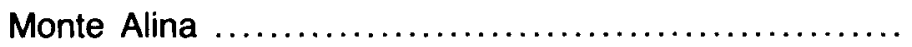 & 108,60 \\
\hline Prado Largo .... & 6,70 \\
\hline Monte Príncipe ... & 3,40 \\
\hline El Chaparral ............. & 65,20 \\
\hline 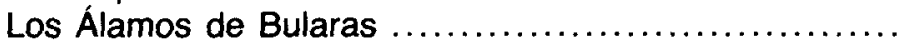 & 24,80 \\
\hline 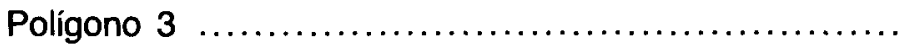 & 6,60 \\
\hline 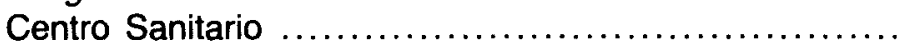 & 2,00 \\
\hline 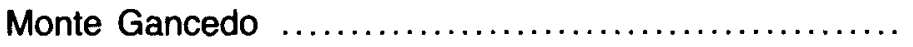 & 118,00 \\
\hline 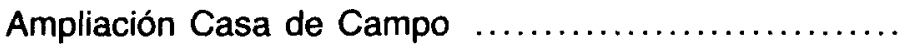 & 344,20 \\
\hline Modificación Sector de Somosaguas $\ldots . \ldots \ldots \ldots \ldots \ldots$ & 122,10 \\
\hline 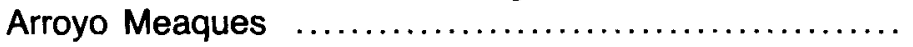 & 116,40 \\
\hline
\end{tabular}

Fuente: PAI, Noroeste.

cela hasta la promoción nacional y multinacional de espacio construido de gran equipamiento.

Las urbanizaciones surgidas en los años setenta van dirigidas a los sectores más solventes de la demanda. En los últimos años las promociones que se realizan en la zona tienen unas características de inferior calidad que las primeras urbanizaciones, con desarrollos urbanisticos seriados (bloques y chalets adosados), que permiten el acceso de la clase media-profesional a un tipo de vivienda y a un sector con unas condiciones medioambientales y de prestigio inexistentes en el resto de la periferia madrileña. Habiéndose consolidado de este modo el carácter suburbano de la zona con respecto a otras zonas del Área Metropolitana Madrileña.

Así pues, si bien en el modelo de concentración metropolitana que se creó alrededor de Madrid intervinieron factores de carácter genérico como un fuerte crecimiento económico, migraciones masivas sobre $\mathrm{Ma}$ drid, condiciones favorables de oferta de trabajo, acelerado incremento comercial, motorización creciente, inversiones infraestructurales de gran magnitud, etc., en el caso de los municipios de la zona noroeste hay que añadir condiciones adicionales. Su formación responde a unas pautas de 
localización y a unas preferencias en demanda de vivienda (de "calidad») de unas capas sociales de solvencia creciente en términos de mercado de la vivienda, pero lógicamente de población reducida, al tratarse de las capas de mayores rentas del Área Metropolitana, únicas capaces de elegir la ubicación y las características de su vivienda en un mercado dominado y controlado por la oferta. 


\section{BIBLIOGRAFIA}

COPLACO, 1981: Directrices de Planeamiento Territorial. Madrid.

Fernández Durán, R., 1980: Transporte, espacio y capital. Madrid. Nuestra Cultura.

Leira, E., Gago J., y Solana, I., 1976: “Madrid: cuarenta años de crecimiento". Ciudad y Territorio, n. ${ }^{\circ} 213$.

Memoria del Plan Bidagor.

Santos Preciado, J. M., 1987: «El modelo de diferenciación residencial del sector Suroeste del AMM». Universidad Complutense de Madrid.

VAlenzuela Rubio, M., 1977: Urbanización y crisis rural en la Sierra de Madrid. Madrid, IEAL. 